\title{
THE MANAGEMENT OF FOOD BOXES PACKING PROBLEMS IN RECTANGULAR CONTAINERS USING THE HEURISTIC METHOD
}

\author{
SIRIMARK PENPARK*1, BOONTAN THAWATCHAI ${ }^{2}$ AND YOTMANEE SANCHAI ${ }^{3}$ \\ ${ }^{1}$ Department of Science and Mathematics, Rajamangala University of Technology Isan, Surin, Thailand. ${ }^{2}$ Faculy of Science \\ and Technology, Rajabhat Maha Sarakham University, Maha Sarakham, Thailand. ${ }^{3}$ Faculy of Science and Technology, \\ Phuket Rajabhat University, Phuket, Thailand.
}

*Corresponding author: penpark.si@rmuti.ac.th

Submitted final draft: 15 September 2020 Accepted: 23 September 2020

http://doi.org/10.46754/jssm.2021.02.014

\begin{abstract}
The increase in consumer demand for food has caused issues concerning the delivery of food packages. This is due to the limited volume of containers available for packing food. This in turn has caused problems in the movement and shipment of food boxes, from food manufacturers and postal delivery services. The purpose of this research is to identify an optimum solution for the volume of food containers, so that storage space can be reduced, which in turn will reduce storage costs. It is also desirable to reduce handling and shipment times to achieve greater efficiency in delivery.

In order to achieve this, heuristic algorithms were applied, based on a genetic algorithm (GA), and simulated annealing (SA), which is combined with the Axis Order Test (AOT), and Corner Point Placing (CPP). The computational performance of the GA-AOT, GACPP, SA-AOT and SA-CPP models is then compared. The results showed that the SA-CPP model is more effective compared with the SA-AOT, GA-CPP and GA-AOT models, as the number of containers was optimized to be at the minimum number. This resulted in a shorter packaging time, and provides the desired reduction of costs in shipment of food containers.
\end{abstract}

Keywords: Management, food packing, heuristic method, genetic algorithm and simulated annealing.

\section{Introduction}

In the last 5 years, the gross domestic product (GDP) for goods distribution in Thailand was reported to be nearly 1 million baht. Accordingly, over 80 percent of the distribution of goods was associated with the distribution by ground transport, compared with other methods of transport. This resulted in high costs due to distribution by air transport. However, ground-transported distribution has many restrictions, such as operating time, loading space and limited routes. Transportation affects the distribution of raw food and other sensitive food products as they are easily damaged and spoiled (Hammond et al., 2015). To increase the quality of food products and economic relevance, Józefowska et al. (2018) showed that food industries require the optimization of the logistic chains, such as operating time, costs and loading space. Therefore, the management of a three-dimensional (3D) food packing system is introduced.

In order to distribute more food packages with a lower number of vehicles, food boxes should be packed optimally. The result of this is a reduction in transportation costs (Gürbüz et al., 2009) and operating time. The problem of packing all boxes into a container is called the $3 \mathrm{D}$ packing problem. Generally, container packing problems can be classified into two cases, which are (i) the homogeneity problem, where a container consists of identical boxes and (ii) the heterogeneous problem, where different size of boxes are used (Salam \& Khan, 2015). Furthermore, the increase in the number of boxes leads to the increase in the optimal arrangements of boxes. To solve the 3D packing problem (Hammond et al. 2015; Oliveira et al., 2016; Mahvash et al., 2017), heuristics algorithms are used. 
The heuristic method is widely used for optimization problems, especially packing problems. The term heuristic refers to algorithms that are used to find the best optimal solutions, and they find it fast and efficiently, but there is no guarantee that the best solution will be found (Shin and Young, 2017; Oliveira et al., 2020). Consequently, the heuristic algorithms may be considered as a best approximation to the solution to the problem. The heuristic algorithm is employed to give an approximate solution, which is sufficient over the option of obtaining an exact solution as exact solutions are computationally expensive.

The motivation for solving this problem came from the distribution of food via Thailand's postal system, or via private companies distributing food during the Covid-19 outbreak. The volume of online purchases has increased among consumers, because it is very likely they have remained in their home to isolate themselves from viral infections. However, the increase in online purchases has resulted in the delay in food delivery. The purpose of this research is to propose the management of a fast and effective food packing problem in rectangular containers by using a heuristic algorithm combined with genetic algorithm (GA) and simulated annealing (SA).

\section{Material and Methods}

\section{Three-dimensional Food Packing Solution}

Throughout this section, the three-dimensional packing management for food boxes, which preserve the axis order test (AOT) and corner point placing (CPP), was explained. This work is based on the following conditions: (i) the items cannot overlap its boundary, (ii) the boxes are strong enough for overlapping and (iii) the food in this research were assumed to be dried food, instant food and snacks, which are lightweight compared with fresh food.

\section{Axis Order Test (AOT)}

The AOT is used in three-dimensional food packing. This idea comes from the bottom left method in 2D. Each item is place with its bottom down of the object and as far as possible to the left, as illustrated in Figure 1(i). The process of this method is described in the Figure 2, supposing that $\mathrm{X} \times \mathrm{Y} \times \mathrm{Z}$ is the size of the container, $R x \times R y \times R z$ is the size of food box and $\mathrm{N}$ is the total number of items.

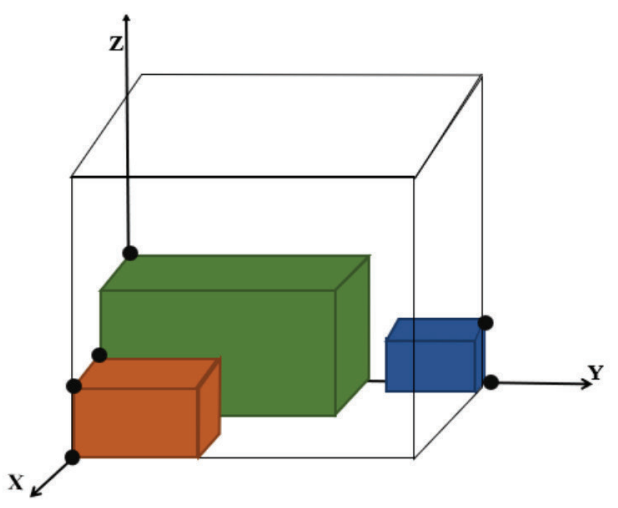

(ii)

Figure 1: Example model for food boxes packing: (i) AOT and (ii) CPP 


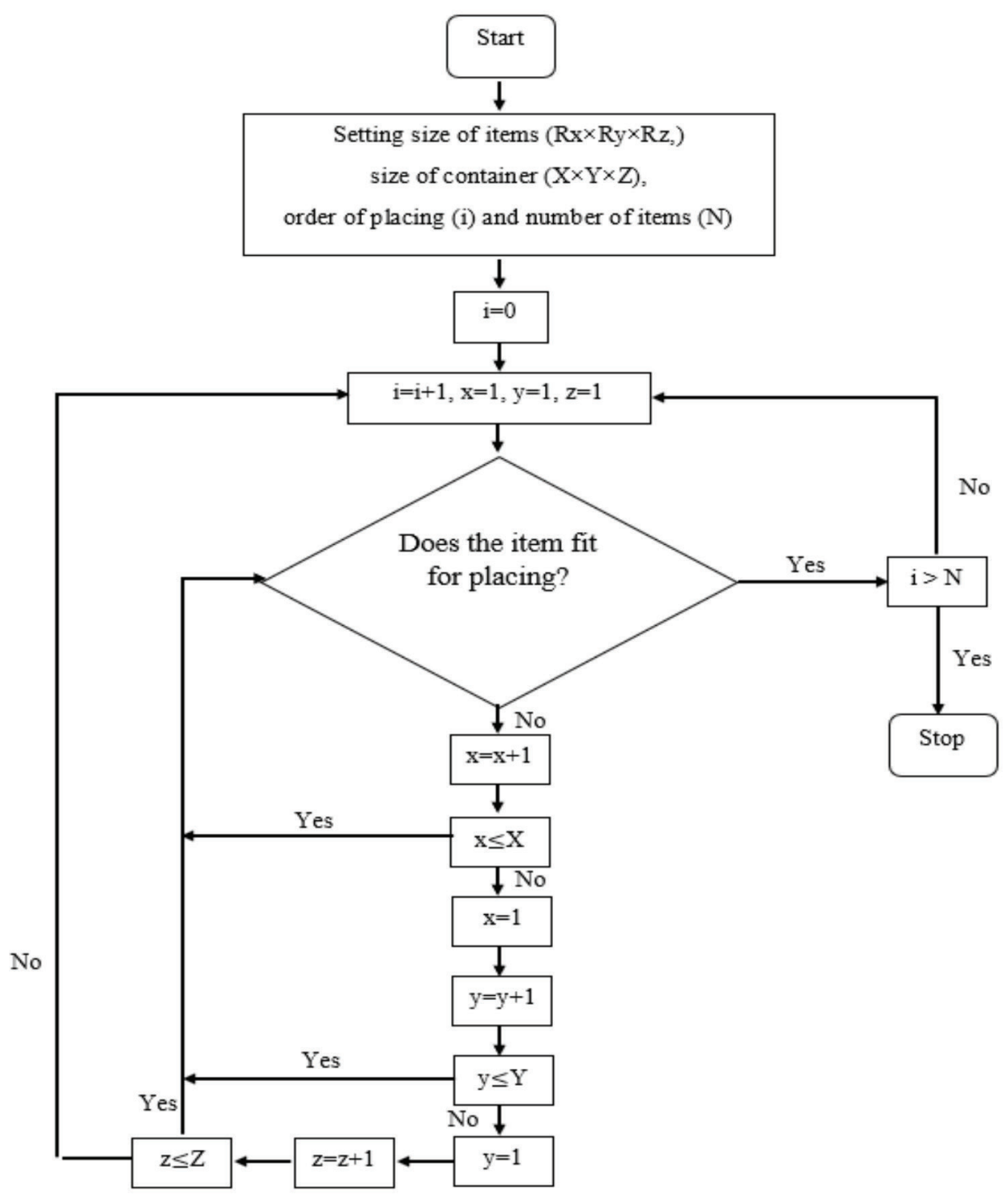

Figure 2: An Illustration of the AOT diagram

\section{Corner Point Placing (CPP)}

The CPP method is based on the corner point, which is the intersection of the three planes formed by the top, bottom, and right sides of items already placed in a container, as illustrated in Figure 1(ii). The food boxes that are already packed cannot move further down, top or backward. When a new food box is placed into container, its position cannot intercept the already packed box. Therefore, the set of all corner points in the bin define the border between the empty region and the occupied region (Martello et al., 2000; de Almeida et al., 2010). Along with the CCP problem, we assume that $\mathrm{N}$ is the number of boxes, $\mathrm{P}$ is the set of all points that the next boxes can be placed and $\mathrm{U}=\mathrm{P}_{0}$. The first box with size $\mathrm{X} 1 \times \mathrm{Y} 1 \times \mathrm{Z} 1$, is placed at the coordinate of the origin. After the first box is placed, the new 3 points $\left(\left(0+X_{1}, 0,0\right)\right.$, $\left(0,0+Y_{1}, 0\right)$ and $\left.\left(0,0,0+Z_{1}\right)\right)$ of the origin appear 
at the corner of the first box, excluding the inside corner of the old origin $(0,0,0)$. The next boxes are placed at the new origin points. If the boxes are not suitable, others are replaced instead of the old ones. The algorithm for finding the order of the placing is presented in Figure 3.

\section{Genetic Algorithm (GA)}

The GA is carried out in 5 steps as follows:

\section{Step 1: Encoding of Chromosomes}

The encoding of chromosomes depends on the problem. The permutation encoding that is used to order the number of food boxes is determined in this study. In permutation encoding, a string of numbers represent the number in a sequence as shown in Table 1.

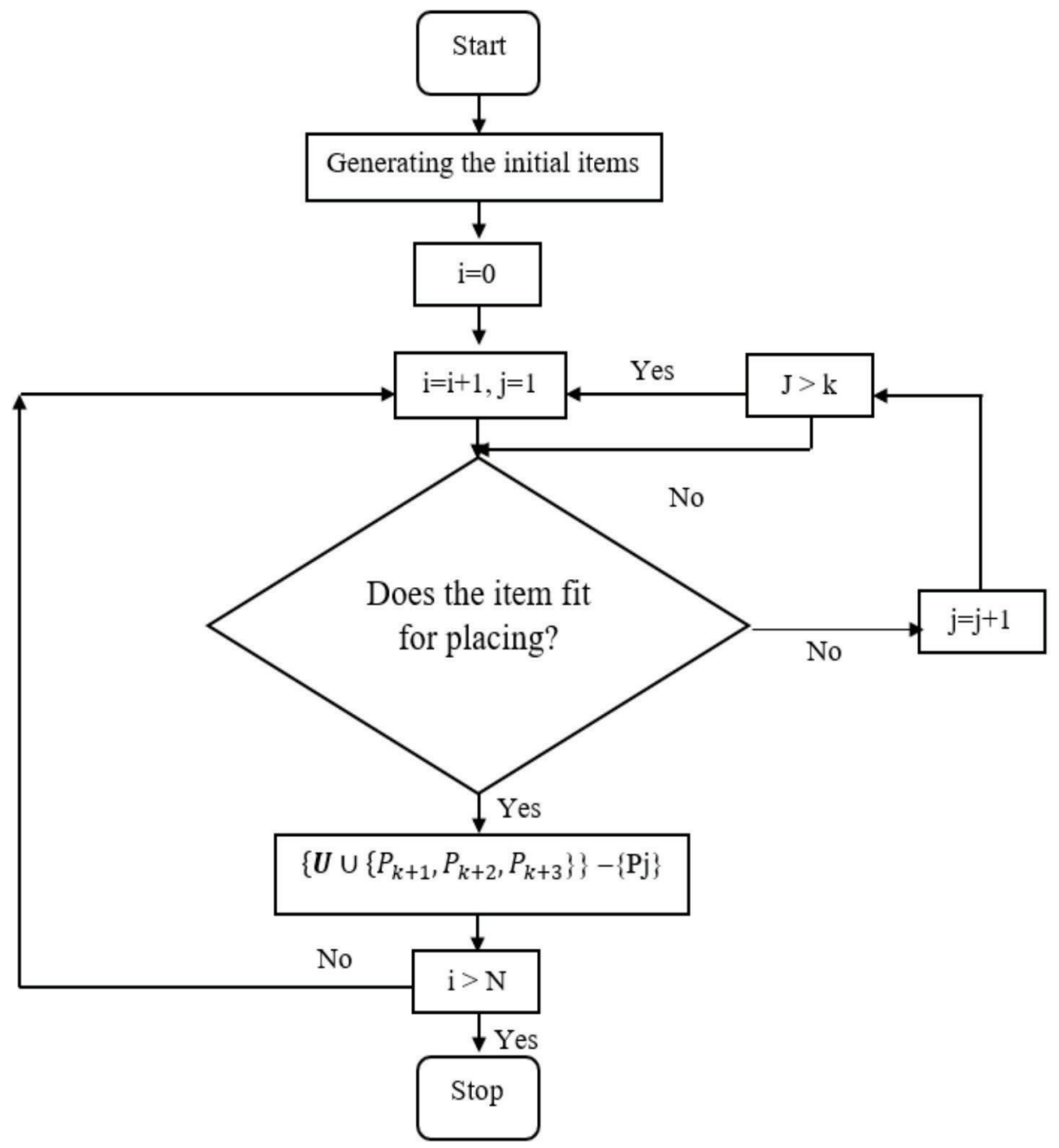

Figure 3: The CPP flowchart

Table 1: An example of permutation encoding

\begin{tabular}{|l|l|l|l|l|l|l|l|}
\hline Chromosome A & 7 & 3 & 1 & 6 & 5 & 2 & 4 \\
\hline Chromosome B & 2 & 1 & 5 & 4 & 3 & 6 & 7 \\
\hline
\end{tabular}




\section{Step 2: Fitness Function}

The fitness function, or Evaluation Function, determines how "fit" or how "good" an individual is. This function gives a fitness score to each individual. The scaled fitness function is used to calculate respective selection probabilities. It can be defined as follows:

$$
\operatorname{prob}=\frac{\text { fitness }\left(x_{i}\right)}{\sum_{i=1}^{n} \operatorname{fitness}\left(x_{i}\right)} .
$$

Here, $n$ is the size of population

$$
\text { fitness }\left(\mathrm{x}_{\mathrm{i}}\right)=\frac{\text { fmax }-\mathrm{fmin}}{\mathrm{n}} \text {. }
$$

According to this scheme, the probability in which an individual is selected for reproduction is based on its fitness score.

\section{Step 3: Selection}

The first genetic operator is selection, where this operator takes place in the basic generic algorithm (Shopova \& Vaklieva-Bancheva, 2006). The idea of selection is to select fit chromosome from our population that can create an offspring. Two pairs of parents are selected according to the fitness scors. The chromosome with a high fitness score has more chance to be selected for reproduction.

\section{Step 4: Crossover}

Crossover is a genetic operator that generates new generation from the parent chromosomes. For every two parents, the crossover takes place by selecting a random point in the chromosome and then exchanging the genes of the paired chromosomes between those points to generate new offspring as shown in Figure 4.

\section{Step 5: Mutation}

Mutation is the changing of the genetic sequence in a chromosome from its initial state with a certain probability (Pan et al., 2015). Figure 5 shows an example of mutation.

\section{Simulated Annealing (SA)}

SA is a method that applies in almost every area of optimization (Xin, 2014). This technique approximates the global minimum with a given function, which may process several local minimums. It works by emulating the physical process of crystallization. The concept of annealing in combinations is proposed by Hanan et al.(2017), who show the Metropolis algorithm for approximating the numerical solution of the behavior of a many body system, as shown in Figure 6.

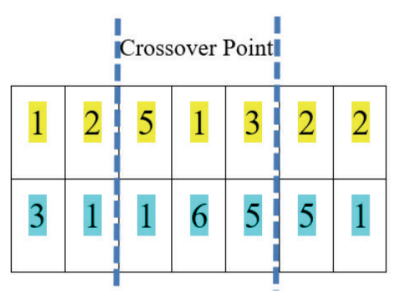

Parent Chromosomes

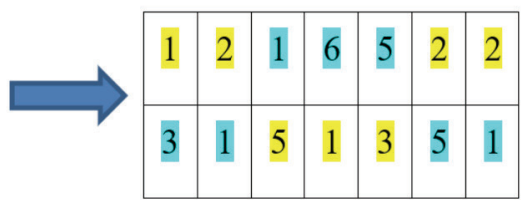

Offspring Chromosomes

Figure 4: An example of a two-point crossover

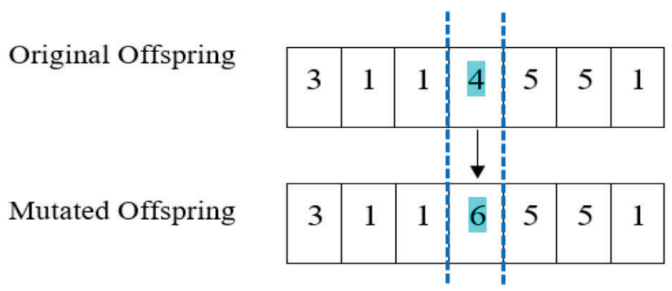

Figure 5: An example of a mutation operator 


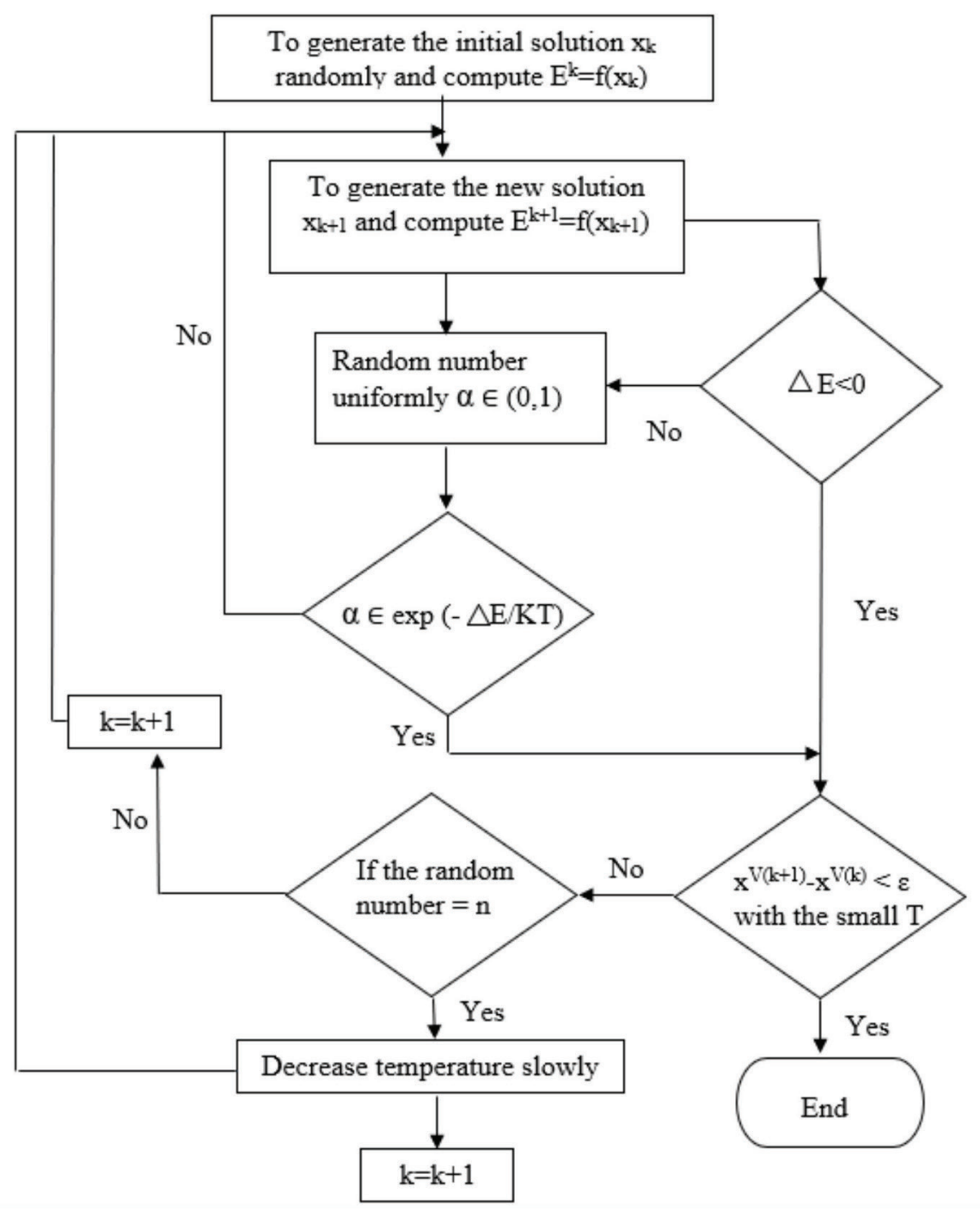

Figure 6: A flowchart of the simulated-annealing algorithm

Following the flowchart in Figure 6, we now suppose that the solution state $\mathrm{x}_{\mathrm{k}}$ becomes state $x_{k+1}$ when the system is subjected to some disturbance. Therefore, the energy of the system has changed from $E^{k}$ to $E^{k+1}$. The probability of accepting in the system is defined as:

$$
\text { prob }=\left\{\begin{array}{cc}
1 & \text { if } \mathrm{Ek}+1 \leq \mathrm{Ek} \\
\exp \left(-\frac{\mathrm{Ek}+1-\mathrm{Ek}}{K T}\right) & \text { if } \mathrm{Ek}+1>\mathrm{Ek} .
\end{array}\right.
$$

\section{Results and Discussion}

The purpose of the current experiment is to examine the efficiency of algorithms between genetic algorithm: GA and simulated annealing: SA. To validate the proposed method, three tests are performed. In order to get the probability results, we created a set of food boxes and containers for food packing based on the characteristics of real-world applications. Throughout this, we assume the food boxes and the containers are rectangular-shaped, yet the items of the food boxes cannot be rotated and 
they can be of different sizes, which is shown in Table 2.

To find the optimal packing process, the comparison between genetic algorithm and simulated annealing were studied. According to this, we set two different sizes of containers $(3 \times 6 \times 3$ and $5 \times 5 \times 4)$. Moreover, the packing problem was categorised into 3 problems. Problem 1 and Problem 2 considered the packing of 19 food boxes, where each box was different in size. Problem 3 consists of 15 food boxes which were 5 replications per size, as shown in Table 2. The results in Table 3 showed that simulated annealing with the corner point placing method (SA-CPP) is a very efficient method as it the shortest operating time, compared with other methods, as shown in Table 3. According to this, the food boxes were optimally packed, which suited the containers, and used less loading spaces. Some examples for the order of food box packing is presented in Figure 7.

As a result, the packing time and loading spaces were optimally used. This had an effect on the operation costs, which decreased. The qualities of food were also maintained. Moreover, the optimization of food box packing might result in an increase in service impression among consumers. This agrees with Phoprasert \& Ayasanond (2018), as they showed that consumers selected logistics service providers according to price and performance as the first and second factors.

Table 2: The detailed size of containers and food boxes, and the number of food boxes

\begin{tabular}{|c|c|c|c|c|c|c|c|c|c|c|c|c|c|c|c|c|c|c|c|c|c|}
\hline & \multirow{2}{*}{\multicolumn{2}{|c|}{$\begin{array}{c}\text { Size of } \\
\text { containers }\end{array}$}} & \multicolumn{19}{|c|}{ Size of food boxes } \\
\hline & & & 1 & 2 & 3 & 4 & 5 & 6 & 7 & 8 & 9 & 10 & 11 & 12 & 13 & 14 & 15 & 16 & 17 & 18 & 19 \\
\hline \multirow{3}{*}{$\begin{array}{c}\text { Problem } \\
1\end{array}$} & ${ }^{\dagger} \mathrm{L}$ & 3 & 3 & 1 & 3 & 1 & 2 & 2 & 2 & 1 & 2 & 3 & 3 & 3 & 2 & 1 & 3 & 2 & 2 & 1 & 2 \\
\hline & ${ }^{*} \mathrm{~W}$ & 6 & 6 & 6 & 3 & 3 & 5 & 3 & 5 & 1 & 6 & 2 & 4 & 5 & 1 & 1 & 6 & 3 & 2 & 1 & 1 \\
\hline & ${ }^{\dagger} \mathrm{H}$ & 3 & 1 & 2 & 3 & 3 & 3 & 2 & 1 & 3 & 1 & 2 & 1 & 1 & 1 & 3 & 1 & 2 & 3 & 1 & 3 \\
\hline \multirow{3}{*}{$\begin{array}{c}\text { Problem } \\
2\end{array}$} & ${ }^{\dagger} \mathrm{L}$ & 5 & 3 & 5 & 4 & 2 & 3 & 2 & 5 & 2 & 1 & 1 & 1 & 5 & 3 & 1 & 3 & 4 & 4 & 3 & 4 \\
\hline & ${ }^{\star} \mathrm{W}$ & 5 & 3 & 2 & 5 & 1 & 3 & 5 & 3 & 1 & 2 & 1 & 4 & 2 & 5 & 3 & 5 & 3 & 4 & 1 & 1 \\
\hline & ${ }^{\dagger} \mathrm{H}$ & 4 & 1 & 3 & 2 & 4 & 2 & 1 & 1 & 1 & 1 & 3 & 4 & 4 & 3 & 4 & 3 & 2 & 2 & 3 & 1 \\
\hline \multirow{3}{*}{$\begin{array}{c}\text { Problem } \\
3\end{array}$} & ${ }^{\dagger} \mathrm{L}$ & 5 & 2 & 2 & 2 & 2 & 2 & 3 & 3 & 3 & 3 & 3 & 3 & 3 & 3 & 3 & 3 & & & & \\
\hline & ${ }^{\star} \mathrm{W}$ & 5 & 3 & 3 & 3 & 3 & 3 & 4 & 4 & 4 & 4 & 4 & 3 & 3 & 3 & 3 & 3 & & & & \\
\hline & ${ }^{\dagger} \mathrm{H}$ & 4 & 1 & 1 & 1 & 1 & 1 & 2 & 2 & 2 & 2 & 2 & 2 & 2 & 2 & 2 & 2 & & & & \\
\hline
\end{tabular}

${ }^{\dagger} \mathrm{L}$ means length, ${ }^{\star} \mathrm{W}$ means width and ${ }^{\dagger} \mathrm{H}$ means height. 
Table 3: A comparison of the three problems between genetic algorithms and simulated annealing

\begin{tabular}{|c|c|c|c|c|}
\hline \multicolumn{2}{|c|}{ Method } & \multirow{2}{*}{$\begin{array}{c}\text { Volume } \\
54\end{array}$} & \multirow{2}{*}{$\begin{array}{c}\text { Order of Placing } \\
13,9, \mathbf{1 9}, \mathbf{1 6}, 15, \mathbf{8}, 7,11,2, \mathbf{1}, \mathbf{1 8}, \mathbf{1 4}, \mathbf{6}, \mathbf{5}, \mathbf{3}, \mathbf{4}, 10,17,12\end{array}$} & \multirow{2}{*}{$\begin{array}{c}\text { Time(s) } \\
42.10\end{array}$} \\
\hline Problem 1 & GA-AOT & & & \\
\hline & GA-CPP & 54 & $18,13,12,16,15,8,7,6,4,5,2,1,3,10,9,11,14,17,19$ & 20.69 \\
\hline & SA-AOT & 54 & $1,13,15,16,19,2,12,3,10,7,17,9,14,6,18,5,4,8,11$ & 49.21 \\
\hline & SA-CPP & 54 & $13,12, \mathbf{1 7}, \mathbf{5}, \mathbf{1 9}, 16,2, \mathbf{1 4}, \mathbf{1}, \mathbf{3}, 6, \mathbf{1 1}, \mathbf{7}, \mathbf{4}, 18, \mathbf{1 0}, \mathbf{9}, \mathbf{8}, \mathbf{1 5}$ & 17.17 \\
\hline \multirow[t]{4}{*}{ Problem 2} & GA-AOT & 98 & $4,2,12, \mathbf{1 1}, \mathbf{7}, \mathbf{3}, \mathbf{1}, 19,18, \mathbf{1 7}, \mathbf{1 6}, \mathbf{1 5}, \mathbf{1 3}, \mathbf{1 0}, 9, \mathbf{1 4}, 8, \mathbf{6}, \mathbf{5}$ & 53.09 \\
\hline & GA-CPP & 97 & $15,12,4,18,14,13,11,9,7,19,1,10,6,8,16,5,3,2,17$ & 21.21 \\
\hline & SA-AOT & 98 & $1,12,2,18, \mathbf{5}, 8, \mathbf{1 4}, \mathbf{1 5}, \mathbf{4}, \mathbf{1 3}, \mathbf{3}, \mathbf{1 7}, \mathbf{6}, 10,7,9, \mathbf{1 6}, \mathbf{1 9}, 11$ & 72.69 \\
\hline & SA-CPP & 99 & $15, \mathbf{5}, 19, \mathbf{1 6}, \mathbf{1 3}, \mathbf{1 8}, \mathbf{1 7}, \mathbf{2}, \mathbf{1 2}, \mathbf{1 0}, \mathbf{3}, \mathbf{6}, 1,11,14,8, \mathbf{7}, \mathbf{9}, 4$ & 17.17 \\
\hline \multirow[t]{4}{*}{ Problem 3} & GA-AOT & 72 & $10,7,15,12,13,4,9,3,2,14,5,1,8,11,6$ & 98.12 \\
\hline & GA-CPP & 72 & $10,8,15,14,13,9,5,4,11,1,2,3,7,6,12$ & 19.38 \\
\hline & SA-AOT & 72 & $\mathbf{9}, 4,1,7, \mathbf{6}, \mathbf{2}, 10, \mathbf{1 5}, 5, \mathbf{1 3}, \mathbf{1 1}, 8,3, \mathbf{1 4}, \mathbf{1 2}$ & 58.55 \\
\hline & SA-CPP & 72 & $4,7,8, \mathbf{6}, \mathbf{1 0}, 2, \mathbf{1 1}, \mathbf{1 2}, \mathbf{1 3}, 3,5, \mathbf{1 4}, \mathbf{9}, \mathbf{1}, \mathbf{1 5}$ & 17.64 \\
\hline
\end{tabular}
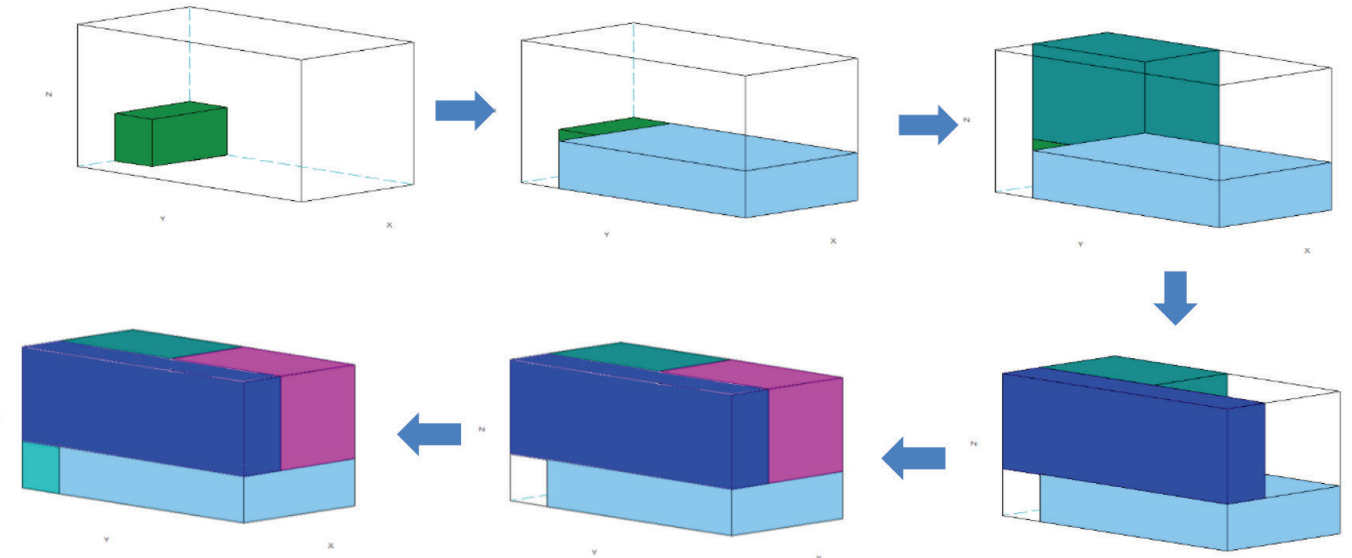

Figure 7: Example of box packing order using SA-CPP (problem 1)

Note: the food boxes with the grey shade were packed into other containers.

\section{Conclusion}

This paper presents the heuristic method to solve the three-dimensional food box packing problem. The experimental results showed that the corner point placing algorithm with simulated annealing could solve food box packing problems as it showed a reduction in operating time and an increase in space utilization. However, to complete the food boxes packing management, the strength of food boxes and the pattern of box packing should be studied more in the future. 


\section{Acknowledgements}

We would like to express apprecation to our respective universities for funding this study.

\section{References}

de Almeida, A., \& Figueiredo, M. B. (2010). A particular approach for the Threedimensional Packing Problem with additional constraints. Computers \& Operations Research, 37(11), 1968-1976.

Gürbüz, M. Z., Akyokuş, S., Emiroğlu, İ., \& Güran, A. (2009). An efficient algorithm for 3D rectangular box packing. Applied Automatic Systems: Proceedings of Selected AAS 2009 Papers, 131-134

Hammond, S. T., Brown, J. H., Burger, J. R., Flanagan, T. P., Fristoe, T. S., MercadoSilva, N., Nekola, J. C., \& Okie, J. G. (2015). Food Spoilage, Storage, and Transport: Implications for a Sustainable Future. BioScience, 65(8), 758-768.

Hanan M. G., Bryan G. S. A., \& Walid A.-K. (2017). Three-Dimensional Container Loading: A Simulated Annealing Approach. International Journal of Applied Engineering Research, 12(10), 1290-1304.

Józefowska, J., Pawlak, G., Pesch, E., Morze, M., \& Kowalski, D. (2018). Fast truck-packing of 3D boxes. Engineering Management in Production and Services, 10(2), 29-40.

Mahvash, B., Awasthi, A., \& Chauhan, S. (2017). A column generation-based heuristic for the three-dimensional bin packing problem with rotation. Journal of the Operational Research Society, 1-13.

Martello, S., Pisinger, D., \& Vigo, D. (2000). The three-dimensional bin packing problem. Operations research, 48(2), 256-267.
Oliveira, J. F., Neuenfeldt Júnior, A., Silva, E., \& Carravilla, M. A. (2016). A survey on heuristics for the two-dimensional rectangular strip packing problem. Pesquisa Operacional, 36(2), 197-226.

Oliveira, Ó., Matos, T., \& Gamboa, D. (2020). Adaptive Sequence-Based Heuristic for the Three-Dimensional Bin Packing Problem. International Conference on Learning and Intelligent Optimization, 11968, 69-76.

Pan, J. C.-H., Shih, P.-H., Wu, M.-H., \& Lin, J.H. (2015). A storage assignment heuristic method based on genetic algorithm for a pick-and-pass warehousing system. Computers \& Industrial Engineering, 81, 1-13.

Phoprasert, N., \& Ayasanond, C. (2018). Logistics Service Provider Management Among Thailand Food Export Entrepreneurs. Journal of Logistics and Supply Chain College, 4(2), 117-128.

Salam, M. A., \& Khan, S. A. (2015). Simulation based decision support system for optimization; A case of Thai logistics service provider. Industrial Management \& Data Systems, 116(2), 236-254.

Shin, W. S., \& You, J. J. (2017). Heuristic for the assort-packing and distribution problem in the fashion apparel industry. International Journal of Production Research, 56(9), 3116-3133.

Shopova, E. G., \& Vaklieva-Bancheva, N. G. (2006). BASIC-A genetic algorithm for engineering problems solution. Computers \& chemical engineering, 30(8), 1293-1309.

Xin, S. Y. (2014). Nature-inspired optimization algorithms. Elsevier, 67-75. 